\title{
Racial differences in disability after stroke
}

\section{Results from a nationwide study}

Pit

James F. Burke, MD, MS

Vicki A. Freedman, PhD

Lynda D. Lisabeth, PhD

Devin L. Brown, MD, MS

Adrianne Haggins, MD, MS

Lesli E. Skolarus, MD, MS

Correspondence to Dr. Burke: jamesbur@umich.edu

\section{ABSTRACT}

Objective: We sought to characterize racial differences in disability among older stroke survivors.

Methods: A cross-sectional study of 806 self-reported stroke survivors from the 2011 National Health and Aging Trends Study was performed. Race was based on self-report. Primary outcome was activity limitations (requiring assistance with mobility, self-care, and household activities). Secondary outcome was participation restrictions, which were defined as reductions/absence in valued social activities because of health. Physical capacity was measured by a validated scale (0 low-12 high). Logistic regression was used to estimate average marginal effects of activity limitations and participation restrictions by race before and after adjusting for sociodemographics, comorbidities, and physical and cognitive capacity.

Results: Non-Hispanic black participants had lower physical capacity than non-Hispanic white participants (mean 5.1 vs 6.9, $p<0.01$ ). For most activities, black participants had significantly greater limitations than white participants. These differences persisted after accounting for sociodemographic factors and comorbidities, but largely became nonsignificant after accounting for physical capacity. The only unadjusted racial difference in participation restriction was in religious service attendance (18.2\% of white participants vs $28.6 \%$ of black participants, $p<0.01$ ).

Conclusion: After stroke, black individuals have a greater prevalence of activity limitations than white individuals, largely due to their greater physical capacity limitations. Further understanding of the causes of racial differences in capacity after stroke is needed to reduce activity limitations after stroke and decrease racial disparities. Neurology ${ }^{\circledR}$ 2014;83:390-397

\section{GLOSSARY}

GAD-2 = Generalized Anxiety Disorder-2 questionnaire; GWTG-Stroke $=$ Get with the Guidelines-Stroke; NIHSS $=$ NIH Stroke Scale; NHATS = National Health and Aging Trends Study; NHIS = National Health Interview Survey; PHQ-2 = Patient Health Questionnaire-2; tPA = tissue plasminogen activator.

Currently, there are 7 million US stroke survivors, and this number is likely to increase substantially given the aging of the US population and declining stroke mortality. ${ }^{1-3}$ Non-Hispanic black individuals have twice as many strokes as non-Hispanic white individuals and racial disparities in stroke incidence have worsened over time. ${ }^{4-6}$

Estimates of racial disparities in poststroke activity limitations have varied widely. Results have ranged from better short-term outcomes in community-dwelling black individuals as measured by the modified Rankin Scale ${ }^{7}$ to more severe activity limitations as measured by the Barthel Index ${ }^{8}$ to no difference in long-term activity limitations as measured by the Barthel Index compared to white individuals. ${ }^{9}$ The contradictory findings from these primarily single-community studies with small sample sizes raise the question of whether, and to what extent, poststroke disability differences exist between black and white individuals in the broader population. Moreover, despite recommendations from the Institute of Medicine to broaden studies of disability beyond essential daily activities to include participation in valued social and civic activities, ${ }^{7,10}$ racial differences in poststroke participation have rarely been investigated. One study has suggested that black individuals are more likely than white individuals to report limitations in going out for enjoyment,

From the Stroke Program (J.F.B., L.D.L., D.L.B., L.E.S.), Institute for Social Research (V.A.F.), and Departments of Epidemiology (L.D.L.) and Emergency Medicine (A.H.), University of Michigan, Ann Arbor.

Go to Neurology.org for full disclosures. Funding information and disclosures deemed relevant by the authors, if any, are provided at the end of the article. 
participating in social activities, and doing things to relax at home, ${ }^{11}$ but factors accounting for such disparities have not been explored. Thus, in this study we characterize and explore reasons for racial differences in activity limitations and participation restrictions after stroke in a national sample of community-dwelling stroke survivors.

METHODS Data source and population. Stroke survivors were identified in the National Health and Aging Trends Study (NHATS). NHATS is an annual face-to-face interview by trained study personnel of over 8,000 Medicare beneficiaries ages 65 and older in their place of residence. If the selected Medicare beneficiary could not complete the interview, a proxy respondent was interviewed. The first round, which took place in 2011, oversampled black participants and people in older age groups. Response rates were $72 \%$ at baseline; analytic weights take into account differential probabilities of selection and nonresponse and allowed for generalization to the Medicare population. Nearly 900 stroke survivors living in the community (including residential care settings other than nursing homes) were identified (738 by self-report and 154 by proxy report) based on an affirmative response to: "Has a doctor has ever told you that you had a stroke?"12 Race and ethnicity were determined by self-report. Due to the small sample size of other race/ethnicities $(9.7 \%$ of the overall sample), our analysis was limited to white and black participants for this analysis.

Outcomes: Activity limitations and participation restrictions. Activity limitation measures in the NHATS disability protocol have been validated and previously described. ${ }^{13}$ NHATS asked about help with 7 self-care and mobility activities: eating, bathing/showering, toileting, dressing, getting out of bed, getting around within one's home, and leaving one's home. In addition, receipt of help for health- or functioningrelated reasons was assessed for 5 household activities: doing own laundry, grocery shopping, making hot meals, handling bills/banking, and administering medications.

In an effort to capture ability to engage in valued social and civic activities, NHATS asked respondents whether they participated in the following activities in the last month: visited with friends/family not living with them either in their home or the home of their friend/family member; attended religious services or participated in clubs, classes, or other organized activities; and gone out for enjoyment (dinner, a movie, or to gamble, hear music, or see a play)..$^{13}$ Each activity had follow-up questions to elicit how important the activity was to the respondents and whether their health or functioning had restricted their participation. Respondents were considered to have a participation restriction if they reported that they valued the activity some or a lot and that their health or functioning limited their participation. A previously validated dichotomous summary score to identify any participation restriction (yes vs no) in valued activities due to health was also created. ${ }^{13}$

Standard protocol approvals, registrations, and patient consents. This study protocol was reviewed by the University of Michigan Medical Institutional Review Board and was deemed to be not regulated as it relied on a publicly available, de-identified dataset.

Potential confounders: Sociodemographic factors, comorbidities, and physical and cognitive capacity. NHATS collects detailed data on a variety of variables that may confound (or in some cases mediate) the associations of race with activity limitations and participation restriction. Several variables reflecting sociodemographic factors, including age, sex, education, marital status, and income, are collected. Educational status was collapsed into 3 categories: less than high school, high school graduate, and college graduate or beyond. NHATS also queried marital status, which we dichotomized into married vs unmarried for this analysis. Income was missing for $31 \%$ of cases, and NHATS imputed values for each missing observation; all observations were collapsed into quintiles. Self-reported comorbidities-myocardial infarction, coronary artery disease, hypertension, diabetes, cancer, lung disease, dementia, osteoporosis, and arthritis-were also individually included. The Patient Health Questionnaire (PHQ-2) and the Generalized Anxiety Disorder questionnaire (GAD-2) were used to measure depressive and anxiety-related symptoms. ${ }^{14,15}$

NHATS measures both self-reported and performance-based measures of capacity. ${ }^{13}$ The self-reported physical capacity measures asked whether the stroke survivor could perform tasks independently and without the use of assistive devices in the last month. Tasks were paired into less and more challenging functions. ${ }^{13} \mathrm{~A}$ summary self-reported physical capacity index was created, with 1 point for every easy task and 2 points for every more challenging task performed (scores 0-12). ${ }^{13}$ The performance-based measures of physical capacity include the Short Physical Performance Battery, a validated assessment tool for measuring lower extremity function consisting of a timed $4 \mathrm{~m}$ walk, repeated chair stands, and a series of balance tests (scores 0 most impaired -12 least impaired). ${ }^{16}$

Respondents also underwent cognitive testing, which included a 10 -word immediate and delayed recall ${ }^{17}$ and the NHATS categorical scoring of the clock draw, previously used in stroke survivors. ${ }^{18}$ Cognitive capacity was summarized as the sum of correct immediate and delayed recall words scores (0-20) and the categorical NHATS clock-drawing scoring system $(0=$ unrecognizable to $5=$ accurate).

Statistical analysis. Descriptive statistics were used to compare white and black participants on sociodemographics and comorbidities after applying survey weights. Our primary analysis estimated the association between race and individual activity limitations using survey-weighted logistic regression models to predict the dependent variable. Analyses were repeated for each participation restriction. For each activity limitation or participation restriction, we then built a series of models to sequentially explore the importance of prespecified groups of potentially explanatory variables: (1) sociodemographic factors (age, sex, education, marital status, income), comorbidities, depressive symptoms, and anxiety symptoms; (2) self-reported physical capacity; and (3) cognitive capacity. For each model, the proportion of white participants and black participants with a given activity limitation or participation restriction was estimated using average marginal effects and compared using Wald tests. The primary analyses were repeated in the NHATS population that did not self-report a history of stroke to determine whether racial differences and patterns of differences in activity limitations in the stroke population were likely to be attributable to stroke or to another cause (e.g., differential effects of aging on activities by race). A secondary analysis repeated the primary set of models using performance-measured capacity instead of self-reported capacity. This analysis was secondary because performance data were missing for $15.6 \%$ of stroke survivors. All analyses were performed using Stata 12 (Stata Statistical Software: release 12; StataCorp LP, College Station, TX).

RESULTS There were 806 stroke survivors, of which 581 were white and 228 were black. Due to 
Table 1 Sociodemographic factors, comorbidities, and physical and cognitive capacity by race among stroke survivors

\begin{tabular}{|c|c|c|c|}
\hline & $\begin{array}{l}\text { White ( } \mathrm{n} \text { surveyed = } \\
581 ; \mathrm{n} \text { survey- } \\
\text { weighted }= \\
2,790,000 \text { ) }\end{array}$ & $\begin{array}{l}\text { Black ( } n \text { surveyed = } \\
225 ; n \text { survey- } \\
\text { weighted = } \\
356,000 \text { ) }\end{array}$ & $p$ \\
\hline \multicolumn{4}{|l|}{ Demographics, \% } \\
\hline Age, y & & & 0.22 \\
\hline $65-69$ & 16.7 & 21.7 & \\
\hline $70-74$ & 19.9 & 25.0 & \\
\hline $75-79$ & 19.4 & 17.7 & \\
\hline $80-84$ & 22.0 & 16.3 & \\
\hline $85-89$ & 14.1 & 13.3 & \\
\hline $90+$ & 7.9 & 5.9 & \\
\hline Female & 56.6 & 61.8 & 0.27 \\
\hline \multicolumn{4}{|l|}{ SES, \% } \\
\hline Married & 48.1 & 30.7 & $<0.01$ \\
\hline Education & & & $<0.01$ \\
\hline Less than high school & 24.8 & 45.9 & \\
\hline High school graduate & 57.8 & 45.1 & \\
\hline College graduate & 16.3 & 8.5 & \\
\hline Income, \% & & & $<0.01$ \\
\hline Less than $\$ 12,100$ & 17.0 & 40.0 & \\
\hline$\$ 12,101-\$ 21,000$ & 24.2 & 26.3 & \\
\hline$\$ 21,001-\$ 34,409$ & 21.1 & 14.2 & \\
\hline$\$ 34,410-\$ 60,000$ & 22.0 & 13.4 & \\
\hline$\$ 60,001+$ & 15.7 & 6.1 & \\
\hline \multicolumn{4}{|l|}{ Comorbidities, \% } \\
\hline Myocardial infarction & 30.5 & 28.9 & 0.61 \\
\hline Coronary artery disease & 31.6 & 22.5 & 0.04 \\
\hline Hypertension & 75.9 & 91.6 & $<0.01$ \\
\hline Diabetes & 35.5 & 41.3 & 0.18 \\
\hline Cancer & 28.8 & 19.6 & 0.01 \\
\hline Lung disease & 21.4 & 17.6 & 0.22 \\
\hline Dementia & 11.3 & 14.5 & 0.27 \\
\hline Osteoporosis & 28.7 & 19.0 & 0.01 \\
\hline Arthritis & 64.4 & 66.6 & 0.65 \\
\hline \multicolumn{4}{|l|}{ Mood } \\
\hline Depressive symptoms (PHQ-2) & 26.4 & 24.2 & 0.60 \\
\hline Anxiety (GAD-2) & 22.3 & 26.9 & 0.26 \\
\hline \multicolumn{4}{|l|}{ Physical capacity } \\
\hline Self-reported capacity index & 6.9 & 5.1 & $<0.01$ \\
\hline SPPB, \% & & & $<0.01$ \\
\hline $0-3$ & 36.6 & 46.4 & \\
\hline $4-6$ & 23.4 & 20.7 & \\
\hline $7-8$ & 14.8 & 7.2 & \\
\hline $9+$ & 11.3 & 4.4 & \\
\hline
\end{tabular}

Continued oversampling of black participants, survey-weighted estimates of the stroke survivor population are $88.7 \%$ (95\% confidence interval $86.7 \%-90.4 \%$ ) white and $11.3 \%(9.6 \%-13.3 \%)$ black. No significant age or sex differences existed between the racial groups. Black participants had less education, lower income, and were less likely to be married than white participants. With the exception of hypertension, comorbidities (coronary artery disease, cancer, osteoporosis) were more common in white participants than black participants. Physical capacity, both self-reported and performance-based measures, word recall, and clockdrawing were higher in white participants than in black participants (table 1).

Activity limitations were more common in black participants than in white participants for all measured activities, with the exception of receipt of help with eating $(p=0.19)$ and bathing $(p=0.06)$ (table 2). Relative differences ranged from $26 \%$ more limitations among black participants compared to white participants for limitations with administering medications to $61 \%$ more limitations among black participants for limitations in handling bills/banking. These differences largely persisted after adjusting for sociodemographic factors and comorbidities (including depressive and anxiety symptoms) and were eliminated after adjusting for physical capacity. Handling bills/banking, which had the largest racial difference, was the exception. For handling bills/banking, the unadjusted proportions $(27.1 \%$ of white participants vs $43.7 \%$ of black participants; $p<0.01$ ) were minimally changed after controlling for sociodemographic factors and comorbidities (27.0\% vs $41.7 \%$; $p<0.01$ ), but were substantially attenuated, although not eliminated after adjusting for physical capacity $(27.6 \%$ vs $36.3 \%$; $p=0.01)$. After adjustment for cognitive capacity, the association was not significant $(27.9 \%$ vs $33.4 \%$; $p=0.10)$. By comparison, in the NHATS population without a reported history of stroke, absolute proportions with activity limitations were considerably lower than in the stroke population (table 3). Similar relative racial differences (14\%-68\%) in activity limitations existed in the nonstroke population; however, unlike in the stroke population, these differences were substantially attenuated or even reversed after adjusting for sociodemographic factors. Adjustment for cognitive capacity further reversed these trends, but generally by a lesser extent than in the stroke population.

Racial differences in participation restrictions were less prominent than in activity limitations. Of the 4 participation restrictions evaluated, an unadjusted difference by race existed only for participation in religious services, with $18.2 \%$ of white participants and $28.6 \%$ of black participants $(p<0.01)$ reporting that they limited participation in this valued activity due to health or functioning. The difference was modestly 
Table 1 Continued

$\begin{array}{llll} & \begin{array}{l}\text { White (n surveyed }= \\ \begin{array}{l}581 ; n \text { survey- } \\ \text { weighted }= \\ 2,790,000)\end{array}\end{array} & \begin{array}{l}\text { Black (n surveyed }= \\ 225 ; n \text { survey- } \\ \text { weighted }= \\ 356,000)\end{array} & \text { p } \\ \begin{array}{l}\text { Cognitive capacity } \\ \text { Words recalled }\end{array} & 10.4 & 7.5 & <0.01 \\ \text { Clock drawing, \% } & 1.2 & 1.2 & <0.01 \\ \text { Not recognizable as a clock } & 4.7 & 9.5 & \\ \text { Severely distorted } & 12.1 & 20.6 & \\ \text { Moderately distorted } & 25.7 & 35.4 & \\ \text { Mildly distorted } & 41.2 & 24.0 & \\ \text { Reasonably accurate } & 11.5 & 2.8\end{array}$

GAD-2 = Generalized Anxiety Disorder-2 questionnaire; PHQ-2 = Patient Health Questionnaire-2; SES = socioeconomic status; SPPB = Short Physical Performance Battery.

reduced when adjusting for sociodemographic factors and comorbidities $(18.6 \%$ vs $26.9 \%$; $p<0.01)$, was further reduced when adjusting for physical capacity $(18.9 \%$ vs $24.5 \% ; p=0.05)$, and was nonsignificant when adjusting for cognitive capacity $(19.0 \%$ vs $23.4 \% ; p=0.13$ ) (table 4).

DISCUSSION In this national sample of older US stroke survivors, we found that black participants have a higher prevalence of limitations in self-care, mobility, and household activities than white participants. These differences suggest a greater stroke burden on black stroke survivors and their informal caregivers. Lower physical capacity in black participants than white participants - rather than socioeconomic differenceswas the most important factor accounting for this association. These patterns differ from those that we observed in the nonstroke population: black participants had a higher prevalence of limitations than white participants, but these differences were largely eliminated after adjusting for sociodemographic factors. Hence, we conclude that the racial differences in activity limitations we have identified following stroke are likely to be stroke-related.

Our findings are consistent with prior findings from REGARDS ${ }^{8}$ and the National Health Interview Survey (NHIS), ${ }^{11}$ which found racial differences in activity limitations following stroke. However, we depart from these studies ${ }^{8,11}$ in finding no racial differences in participation restrictions. It may be that different approaches to measuring participation in NHATS, REGARDS, and NHIS accounts for the different findings. Further research to sort out under what circumstances racial disparities in participation restrictions exist would be valuable.

Our findings also add to the literature by demonstrating that physical capacity differences account for much of the racial disparity in activity limitations

Table 2 Activity limitations by race in stroke survivors

\begin{tabular}{|c|c|c|c|c|c|c|c|c|c|c|c|c|}
\hline & \multicolumn{3}{|c|}{ Unadjusted } & \multicolumn{3}{|c|}{$\begin{array}{l}\text { Adjusted for } \\
\text { sociodemographic factors } \\
\text { and comorbidities }\end{array}$} & \multicolumn{3}{|c|}{$\begin{array}{l}\text { Adjusted for } \\
\text { sociodemographic } \\
\text { factors, comorbidities, } \\
\text { and physical capacity }\end{array}$} & \multicolumn{3}{|c|}{$\begin{array}{l}\text { Adjusted for } \\
\text { sociodemographic } \\
\text { factors, comorbidities, } \\
\text { physical and cognitive } \\
\text { capacity }\end{array}$} \\
\hline & White & Black & p Value & White & Black & p Value & White & Black & p Value & White & Black & p Value \\
\hline \multicolumn{13}{|l|}{ Help with self-care activities } \\
\hline Gets help to eat & 13.5 & 17.3 & 0.19 & 13.5 & 17.7 & 0.15 & 14.2 & 12.7 & 0.53 & 14.4 & 11.8 & 0.28 \\
\hline Gets help bathing & 20.3 & 30.3 & 0.06 & 20.6 & 28.4 & 0.04 & 21.6 & 21.3 & 0.93 & 21.8 & 20.2 & 0.59 \\
\hline Gets help toileting & 8.8 & 13.8 & 0.02 & 8.7 & 14.4 & 0.02 & 9.2 & 10.0 & 0.60 & 9.2 & 9.7 & 0.80 \\
\hline Gets help dressing & 23.3 & 30.9 & 0.04 & 23.2 & 33.1 & $<0.01$ & 24.1 & 25.6 & 0.56 & 24.2 & 24.5 & 0.92 \\
\hline \multicolumn{13}{|l|}{ Help with mobility activities } \\
\hline Gets help to go outside & 23.8 & 32.8 & 0.01 & 23.8 & 34.3 & $<0.01$ & 24.6 & 27.2 & 0.41 & 24.6 & 26.7 & 0.54 \\
\hline Gets help to get around in home & 16.2 & 24.9 & $<0.01$ & 16.3 & 25.4 & $<0.01$ & 16.9 & 19.3 & 0.35 & 17.1 & 18.5 & 0.56 \\
\hline Gets help to get out of bed & 13.0 & 19.7 & 0.02 & 13.1 & 19.6 & 0.03 & 13.8 & 14.1 & 0.88 & 13.9 & 13.4 & 0.84 \\
\hline \multicolumn{13}{|l|}{$\begin{array}{l}\text { Help with household activities due to } \\
\text { health or functioning }\end{array}$} \\
\hline Gets help with laundry & 27.4 & 41.9 & $<0.01$ & 27.3 & 41.7 & $<0.01$ & 28.5 & 31.8 & 0.16 & 28.7 & 30.7 & 0.37 \\
\hline Gets help with shopping & 36.7 & 52.4 & $<0.01$ & 37.1 & 50.5 & $<0.01$ & 38.1 & 42.7 & 0.20 & 38.2 & 41.7 & 0.37 \\
\hline Gets help with preparing hot meals & 32.2 & 42.7 & $<0.01$ & 32.0 & 43.4 & $<0.01$ & 32.9 & 35.5 & 0.38 & 33.2 & 34.0 & 0.74 \\
\hline Gets help with banking or bills & 27.1 & 43.7 & $<0.01$ & 27.0 & 41.7 & $<0.01$ & 27.6 & 36.3 & 0.01 & 27.9 & 33.4 & 0.10 \\
\hline Gets help with managing medications & 26.3 & 33.0 & 0.05 & 26.6 & 31.8 & 0.10 & 27.2 & 26.8 & 0.84 & 27.5 & 25.0 & 0.30 \\
\hline
\end{tabular}

Values are percentages. 
Table 3 Activity limitations by race in the nonstroke National Health and Aging Trends Study population

\begin{tabular}{|c|c|c|c|c|c|c|c|c|c|c|c|c|}
\hline & \multicolumn{3}{|c|}{ Unadjusted } & \multicolumn{3}{|c|}{$\begin{array}{l}\text { Adjusted for } \\
\text { sociodemographic } \\
\text { factors and comorbidities }\end{array}$} & \multicolumn{3}{|c|}{$\begin{array}{l}\text { Adjusted for } \\
\text { sociodemographic } \\
\text { factors, comorbidities, } \\
\text { and physical capacity }\end{array}$} & \multicolumn{3}{|c|}{$\begin{array}{l}\text { Adjusted for } \\
\text { sociodemographic } \\
\text { factors, comorbidities, } \\
\text { physical and cognitive } \\
\text { capacity }\end{array}$} \\
\hline \multicolumn{13}{|l|}{ Help with self-care activities } \\
\hline Gets help to eat & 2.9 & 3.3 & 0.42 & 3.0 & 2.5 & 0.29 & 3.0 & 2.2 & 0.09 & 3.1 & 2.2 & 0.05 \\
\hline Gets help toileting & 2.2 & 3.1 & 0.03 & 2.2 & 2.6 & 0.36 & 2.2 & 2.2 & 0.93 & 2.2 & 2.1 & 0.76 \\
\hline Gets help dressing & 7.4 & 11.0 & $<0.001$ & 7.5 & 9.2 & 0.1 & - & - & & - & - & \\
\hline \multicolumn{13}{|l|}{ Help with mobility activities } \\
\hline Gets help to go outside & 7.9 & 12.0 & $<0.001$ & 7.9 & 9.4 & 0.13 & 8.0 & 8.3 & 0.72 & 8.1 & 8.1 & 0.96 \\
\hline \multicolumn{13}{|l|}{$\begin{array}{l}\text { Help with household activities due to } \\
\text { health or functioning }\end{array}$} \\
\hline Gets help with laundry & 9.7 & 14.4 & $<0.001$ & 10.0 & 11.7 & 0.19 & 10.1 & 10.4 & 0.79 & 10.2 & 10.0 & 0.86 \\
\hline Gets help with shopping & 13.2 & 20.6 & $<0.001$ & 13.9 & 16.5 & 0.03 & 14.1 & 14.9 & 0.45 & 14.2 & 14.3 & 0.91 \\
\hline Gets help with preparing hot meals & 10.6 & 14.4 & $<0.001$ & 11.0 & 12.0 & 0.35 & 11.1 & 10.7 & 0.69 & 11.1 & 10.3 & 0.29 \\
\hline Gets help with banking or bills & 8.0 & 13.4 & $<0.001$ & 8.4 & 10.0 & 0.07 & 8.6 & 9.1 & 0.42 & 8.7 & 8.6 & 0.96 \\
\hline Gets help with managing medications & 6.6 & 10.2 & $<0.001$ & 6.9 & 7.6 & 0.32 & 7.0 & 7.0 & 0.99 & 7.1 & 6.6 & 0.41 \\
\hline
\end{tabular}

Values are percentages.

after stroke. If capacity is causally related to activity limitations as our results suggest, understanding what leads to racial differences in capacity is essential to eliminating disparities in activity limitations after stroke. Racial differences in capacity may be explained by differences in (1) prestroke capacity; (2) biological differences in stroke mechanism or severity; (3) care during the acute stroke period (e.g., hospital quality of care, tissue plasminogen activator (tPA) utilization); (4) postacute rehabilitation care; or (5) factors in the late poststroke period. Of these possibilities, the prestroke and poststroke periods have not been studied as extensively as acute stroke care.
Researchers have shown that prestroke disability is a predictor of poststroke disability ${ }^{7}$; however, little is known about racial differences in prestroke capacity. Conversely, there are substantial data suggesting that there are no major racial differences in stroke mechanism or disease severity. Compared to white individuals, a lower proportion of strokes among black individuals are cardioembolic, ${ }^{19}$ which are associated with large infarcts and high stroke severity. ${ }^{20}$ Consequently, we would anticipate that black participants would have greater poststroke capacity than white participants based on stroke mechanism. In terms of stroke severity, the population-based Northern Manhattan Stroke Study and the Greater

Table 4 Participation restrictions due to health or functioning by race

\begin{tabular}{|c|c|c|c|c|c|c|c|c|c|c|c|c|}
\hline & \multicolumn{3}{|c|}{ Unadjusted } & \multicolumn{3}{|c|}{$\begin{array}{l}\text { Adjusted for } \\
\text { sociodemographic } \\
\text { factors and comorbidities }\end{array}$} & \multicolumn{3}{|c|}{$\begin{array}{l}\text { Adjusted for } \\
\text { sociodemographic } \\
\text { factors, comorbidities, } \\
\text { and physical capacity }\end{array}$} & \multicolumn{3}{|c|}{$\begin{array}{l}\text { Adjusted for } \\
\text { sociodemographic } \\
\text { factors, comorbidities, } \\
\text { physical and cognitive } \\
\text { capacity }\end{array}$} \\
\hline & White & Black & $p$ Value & White & Black & $p$ Value & White & Black & $p$ Value & White & Black & p Value \\
\hline Limited visits with friends and family & 12.9 & 14.3 & 0.63 & 13.4 & 11.6 & 0.53 & 13.5 & 10.3 & 0.21 & 13.6 & 9.9 & 0.15 \\
\hline Limited going out for enjoyment & 13.4 & 12.5 & 0.79 & 13.5 & 13.1 & 0.91 & 13.9 & 10.8 & 0.33 & 13.8 & 11.0 & 0.37 \\
\hline
\end{tabular}

Values are percentages. 
Cincinnati/Northern Kentucky stroke study found no difference in stroke severity (NIH Stroke Scale [NIHSS]) between black and white participants. ${ }^{21,22}$ Similarly, the Get with the Guidelines-Stroke (GWTG-Stroke) Medicare-linked population and a prospective cohort study of veterans also found no clinically meaningful difference in NIHSS by race. ${ }^{23,24}$

Additional data from the acute stroke period suggest that black participants have comparable quality of acute stroke care to white participants and that any differences in the quality of care are too small to explain the substantial racial differences in capacity found in our study. ${ }^{25}$ A GWTG-Stroke study did not find that black participants had consistently lower quality of care than white participants, and when differences existed found only small differences in process-based quality measures by race. ${ }^{25}$ Overall, studies have shown that black participants are less likely to receive tPA than white participants. ${ }^{26,27}$ However, among stroke patients who present to the hospital in under 2 hours, no racial differences in tPA administration exist, ${ }^{25}$ suggesting that racial disparities are mostly due to greater prehospital delay among black participants compared to white participants. Given that the absolute racial disparity in tPA administration is small, and that very few stroke patients overall are treated with $\mathrm{tPA}$, it is unlikely to be the sole explanation for the large disparities in capacity found in this study, although it likely contributes to this difference.

Racial differences in postacute rehabilitation care may also explain some of the racial differences in capacity after stoke. More intensive poststroke rehabilitation has been associated with reduced activity limitations. ${ }^{28}$ Among stroke survivors discharged to institutional postacute rehabilitation care, black participants are more likely to be discharged to less intense rehabilitation environments (i.e., subacute nursing facilities) than more intense ones (i.e., inpatient rehabilitation facilities) compared to white participants. ${ }^{29}$ Racial differences in admission to higher intensity rehabilitation environments is also suggested by the fact that black individuals admitted to inpatient rehabilitation facilities have greater activity limitations compared to white individuals, suggesting that black individuals with less severe strokes are less likely to receive this higher level of care. ${ }^{30}$ Taken together, these findings suggest that the threshold to enter inpatient rehabilitation facilities may be higher in black individuals compared to white individuals. This may represent a missed opportunity for black stroke survivors to acutely improve their capacity, although this requires further study.

Finally, little is known about racial difference in long-term poststroke capacity. Black individuals have greater overall mortality from strokes than white individuals, mostly due to increased stroke incidence among black individuals. ${ }^{4}$ However, black individuals have equal or lower case fatality than white individuals, largely due to their younger age at the time of stroke. ${ }^{4,31}$ Thus, 2 primary hypotheses may contribute to the development of long-term differences in poststroke capacity. First, it may be that black individuals and white individuals recover to the same poststroke capacity level after completing rehabilitation but black individuals then have a steeper longterm decline in capacity. Second, given their younger age at stroke onset ${ }^{32}$ and the equal or lower case fatality, ${ }^{4,31}$ it may be that black individuals live longer after their stroke and although the slope of the decline in capacity is the same, the duration is longer for black individuals. Given that time from stroke could not be measured in this cross-sectional study, this is a possible explanation for the differences in capacity we observed.

The substantial racial differences in activity limitations are not mirrored in participation restrictions. A major difference is that activity limitations represent requiring help with essential daily activities whereas participation restrictions focus on whether valued activities are carried out less often due to health or functioning. Thus, black individuals may be getting help with activities but this has not limited their participation when compared to white individuals. Black individuals have more participation restrictions in religious service attendance than white individuals, which persists similar to activity limitations until accounting for physical capacity. This may be because black individuals are more likely to identify themselves as religious and attend religious services than white individuals ${ }^{33}$ and thus this may be an activity that black individuals value more than white individuals.

This study has limitations. This is a cross-sectional study, thus we cannot determine the number of strokes an individual may have had or the temporal relationship of stroke onset to capacity, activity, and participation measures. Consequently, we cannot determine whether race has differing causal effects on the course of disability after stroke. The diagnosis of stroke was based on self-report; however, the accuracy of stroke self-report in the elderly is reasonably reliable. ${ }^{34,35}$ In addition, stroke rates and the predictiveness of vascular risk factors based on stroke self-report are similar to those from epidemiologic studies. ${ }^{36}$ In addition, stroke rates and the predictiveness of vascular risk factors based on self-report are similar to those from epidemiologic studies. ${ }^{37}$ To the extent that stroke self-report is an imperfect measure, it should not lead to bias by race as the reliability of self-report does not substantially differ by race. ${ }^{36}$ Findings in the NHATS population, which is limited to Medicare recipients, may not generalize to working-age stroke patients, where stroke incidence disparities are most striking. ${ }^{5,38}$ Finally, at 
baseline, NHATS did not interview older adults living in nursing home facilities, thus these results may only be generalized to community-based older adults who are stroke survivors.

Racial differences in poststroke activity limitations exist and racial differences in poststroke capacity seem to play the most important role in this disparity. Longitudinal studies of stroke survivors to clearly define the role of capacity in racial differences in poststroke activity limitations are needed. Given the aging population and the persistence of racial disparities in stroke incidence, determining when and how best to intervene to maximize poststroke capacity and eliminate racial disparities is of great importance.

\section{AUTHOR CONTRIBUTIONS}

Dr. Burke: wrote initial draft of the manuscript, study concept/design, analysis/interpretation of data. Dr. Freedman: study concept/design, analysis/interpretation of data, revision of manuscript for important content, obtained funding, study supervision. Dr. Lisabeth: revision of manuscript for important content. Dr. Brown: revision of manuscript for important content. Dr. Haggins: revision of manuscript for important content. Dr. Skolarus: study concept/design, analysis/interpretation of data, revision of manuscript for important content. All authors gave final approval of the submitted version.

\section{STUDY FUNDING}

Funded by NIH/National Institute of Neurological Disorders and Stroke K23 NS073685 (Dr. Skolarus), NIH/National Institute of Neurological Disorders and Stroke K08NS082597 (Dr. Burke), NIH/NIA U01AG032947 (Dr. Kasper/Dr. Freedman).

\section{DISCLOSURE}

J. Burke receives research support from National Institute of Neurological Disorders and Stroke via K08 NS082597. V. Freedman is funded by NIA U01AG032947. L. Lisabeth is funded by NIH grants R01NS38916, R01NS062675, R01 HL098065, and R01NS070941. D. Brown serves as an editorial board member of Neurology ${ }^{\circledR}$ and Stroke, is funded by NIH grants R01 NS062675, R01 HL098065, and R01 NS070941, received research support from the Blue Cross Blue Shield of Michigan Foundation and Michigan Department of Community Health, and receives research support from the University of Michigan for stroke-related research. A. Haggins received funding from the Robert Wood Johnson clinical scholars program. L. Skolarus is supported by NIH grant K23NS073685. She has also received hotel accommodations from the American Academy of Neurology and the American Neurological Association for their national meeting. She received research support from the Blue Cross Blue Shield of Michigan Foundation and receives research support from the University of Michigan for stroke-related research. Go to Neurology.org for full disclosures.

Received October 11, 2013. Accepted in final form March 4, 2014.

\section{REFERENCES}

1. United States Census Bureau. 2012 National population projections. Available at: http://www.census.gov/population/ projections/data/national/2012.html. Accessed September 10, 2013.

2. Burke JF, Lisabeth LD, Brown DL, et al. Determining stroke's rank as a cause of death using multicause mortality data. Stroke 2012;43:2207-2211.

3. Go AS, Mozaffarian D, Roger VL, et al. Heart disease and stroke statistics: 2013 update: a report from the American Heart Association. Circulation 2013;127:e6-e245.
4. Howard VJ, Kleindorfer DO, Judd SE, et al. Disparities in stroke incidence contributing to disparities in stroke mortality. Ann Neurol 2011;69:619-627.

5. Sacco RL, Boden-Albala B, Gan R, et al. Stroke incidence among white, black, and Hispanic residents of an urban community: the Northern Manhattan Stroke Study. Am J Epidemiol 1998;147:259-268.

6. Kleindorfer DO, Khoury J, Moomaw CJ, et al. Stroke incidence is decreasing in whites but not in blacks: a population-based estimate of temporal trends in stroke incidence from the Greater Cincinnati/Northern Kentucky Stroke Study. Stroke 2010;41:1326-1331.

7. Kissela B, Lindsell CJ, Kleindorfer D, et al. Clinical prediction of functional outcome after ischemic stroke the surprising importance of periventricular white matter disease and race. Stroke 2009;40:530-536.

8. Roth DL, Haley WE, Clay OJ, et al. Race and gender differences in 1-year outcomes for community-dwelling stroke survivors with family caregivers. Stroke 2011;42:626-631.

9. Dhamoon MS, Moon YP, Paik MC, et al. Long-term functional recovery after first ischemic stroke: the Northern Manhattan Study. Stroke 2009;40:2805-2811.

10. Field MJ, Jette A, eds. The Future of Disability in America. Washington, DC: The National Academies Press; 2007.

11. Differences in disability among black and white stroke survivors: United States, 2000-2001. MMWR Morb Mortal Wkly Rep 2005;54:3-6.

12. Kasper JD, Freedman VA. National Health and Aging Trends Study Round 1 User Guide: Final Release. Baltimore: Johns Hopkins University School of Public Health; 2012.

13. Freedman VA, Kasper JD, Cornman JC, et al. Validation of new measures of disability and functioning in the National Health and Aging Trends Study. J Gerontol A Biol Sci Med Sci 2011;66A:1013-1021.

14. Kroenke K, Spitzer RL, Williams JBW. The Patient Health Questionnaire-2: validity of a two-item depression screener. Med Care 2003;41:1284-1292.

15. Kroenke K, Spitzer RL, Williams JBW, et al. Anxiety disorders in primary care: prevalence, impairment, comorbidity, and detection. Ann Intern Med 2007;146:317-325.

16. Guralnik JM, Simonsick EM, Ferrucci L, et al. A short physical performance battery assessing lower extremity function: association with self-reported disability and prediction of mortality and nursing home admission. J Gerontol 1994;49:M85-M94.

17. Welsh K, Butters N, Hughes J, et al. Detection of abnormal memory decline in mild cases of Alzheimer's disease using CERAD neuropsychological measures. Arch Neurol 1991;48:278-281.

18. Adunsky A, Fleissig Y, Levenkrohn S, et al. Clock drawing task, mini-mental state examination and cognitive-functional independence measure: relation to functional outcome of stroke patients. Arch Gerontol Geriatr 2002;35:153-160.

19. White $\mathrm{H}$, Boden-Albala B, Wang C, et al. Ischemic stroke subtype incidence among whites, blacks, and Hispanics: the Northern Manhattan Study. Circulation 2005;111: 1327-1331.

20. Lin H-J, Wolf PA, Kelly-Hayes M, et al. Stroke severity in atrial fibrillation: the Framingham Study. Stroke 1996;27: 1760-1764.

21. Hartmann A, Rundek T, Mast H, et al. Mortality and causes of death after first ischemic stroke the Northern Manhattan Stroke Study. Neurology 2001;57:2000-2005. 
22. Kleindorfer D, Lindsell C, Alwell KA, et al. Patients living in impoverished areas have more severe ischemic strokes. Stroke 2012;43:2055-2059.

23. Qian F, Fonarow GC, Smith EE, et al. Racial and ethnic differences in outcomes in older patients with acute ischemic stroke. Circ Cardiovasc Qual Outcomes 2013;6:284-292.

24. Jones MR, Horner RD, Edwards LJ, et al. Racial variation in initial stroke severity. Stroke 2000;31:563-567.

25. Schwamm LH, Reeves MJ, Pan W, et al. Race/ethnicity, quality of care, and outcomes in ischemic stroke. Circulation 2010;121:1492-1501.

26. Hsia AW, Edwards DF, Morgenstern LB, et al. Racial disparities in tissue plasminogen activator treatment rate for stroke. Stroke 2011;42:2217-2221.

27. Nasr DM, Brinjikji W, Cloft HJ, et al. Racial and ethnic disparities in the use of intravenous recombinant tissue plasminogen activator and outcomes for acute ischemic stroke. J Stroke Cerebrovasc Dis 2013;22:154-160.

28. Kramer AM, Steiner JF, Schlenker RE, et al. Outcomes and costs after hip fracture and stroke. JAMA 1997;277:396-404.

29. Freburger JK, Holmes GM, Ku L-JE, et al. Disparities in postacute rehabilitation care for stroke: an analysis of the state inpatient databases. Arch Phys Med Rehabil 2011;92: 1220-1229.

30. Ottenbacher KJ, Campbell J, Kuo Y-F, et al. Racial and ethnic differences in postacute rehabilitation outcomes after stroke in the United States. Stroke 2008;39:1514-1519.
31. Kleindorfer D, Broderick J, Khoury J, et al. The unchanging incidence and case-fatality of stroke in the 1990s: a population-based study. Stroke 2006;37:2473-2478.

32. Kissela B, Schneider A, Kleindorfer D, et al. Stroke in a biracial population: the excess burden of stroke among blacks. Stroke 2004;35:426-431.

33. Pew Research Religion and Public Life Project. Religious landscape survey. Available at: http://religions.pewforum. org/reports\#. Accessed January 7, 2014.

34. Okura Y, Urban LH, Mahoney DW, et al. Agreement between self-report questionnaires and medical record data was substantial for diabetes, hypertension, myocardial infarction and stroke but not for heart failure. J Clin Epidemiol 2004;57:1096-1103.

35. Engstad T, Bønaa KH, Viitanen M. Validity of self-reported stroke the Tromsø study. Stroke 2000;31:1602-1607.

36. Reitz C, Schupf N, Luchsinger JA, et al. Validity of self-reported stroke in elderly African Americans, Caribbean Hispanics, and whites. Arch Neurol 2009; 66:834-840

37. Glymour MM, Avendano M. Can self-reported strokes be used to study stroke incidence and risk factors? Evidence from the Health and Retirement Study. Stroke 2009;40: 873-879.

38. Kissela BM, Khoury JC, Alwell K, et al. Age at stroke: temporal trends in stroke incidence in a large, biracial population. Neurology 2012;79:1781-1787.

\section{Subspecialty Alerts by E-mail!}

Customize your online journal experience by signing up for e-mail alerts related to your subspecialty or area of interest. Access this free service by visiting http://www.neurology.org/site/subscriptions/etoc.xhtml or click on the "E-mail Alerts" link on the home page. An extensive list of subspecialties, methods, and study design choices will be available for you to choose from-allowing you priority alerts to cutting-edge research in your field!

\section{Inspire. Empower. Lead.}

\section{Apply for AAN Emerging Leaders Forum}

We're looking for the next generation of leaders! Learn skills to become a leader within the American Academy of Neurology (AAN), the world's largest professional association of neurologists. If you're a talented, highly motivated AAN member 45 years of age or younger-or no more than 13 years out of training-interested in learning invaluable skills, behaviors, and tools for leadership success, then apply for the 2014-2015 AAN Emerging Leaders Forum before the August 1, 2014, application deadline. Visit AAN.com/view/lead today! 